\title{
Functional and radiological comparison of transforaminal lumbar interbody fusion method with interbody fusion device versus stand-alone bone graft in lumbar canal stenosis or degenerative lumbar instability
}

\author{
Ashish Kumar Gupta ${ }^{1}$, Jitendra Singh Rathore ${ }^{2}$, Lokpal Singh Bhati2*, \\ Devendra Singh Rathore ${ }^{3}$, R. C. Meena ${ }^{1,4}$
}

\author{
${ }^{1}$ Department of Orthopedics, S. M. S. Medical College, Jaipur, Rajasthan, India \\ ${ }^{2}$ Department of Orthopedics, Dr S. N. Medical College, Jodhpur, Rajasthan, India \\ ${ }^{3}$ Department of Orthopedics, Hinduja Surgical Hospital Khar, Mumbai, Maharashtra, India \\ ${ }^{4}$ Indian Orthopedic Association, New Delhi, India
}

Received: 04 January 2021

Revised: 18 January 2021

Accepted: 19 January 2021

\author{
*Correspondence: \\ Dr. Lokpal Singh Bhati, \\ E-mail: drrattirammeena@gmail.com
}

Copyright: (C) the author(s), publisher and licensee Medip Academy. This is an open-access article distributed under the terms of the Creative Commons Attribution Non-Commercial License, which permits unrestricted non-commercial use, distribution, and reproduction in any medium, provided the original work is properly cited.

\begin{abstract}
Background: Spinal stability is the vertebral ability to maintain their relationship and limit their relative displacements during physiologic postures and loads.

Methods: Hospital based prospective randomized comparative study design between 2 groups included patients of both sex attending SMS hospital Jaipur, from April 2018 to June 2019 or till sample size was achieved, with due permission from institutional ethical committee and review board and after taking written informed consent from patients.

Results: Inter group comparison of VAS score showed same results in both groups which showed statistically nonsignificant results. VAS score showed significantly reduction in both group A and B till the study period. Inter group comparison of ODI score showed same results in both groups which showed statistically non-significant results. ODI score showed significantly reduction in both group A and B till the study period. Inter group comparison of fusion rate score showed same results in both groups which showed statistically non-significant results. Fusion rate score showed significantly increased in both group A and B till the study period and at the 12 month it was $100 \%$ fusion rate.

Conclusions: In the current series, the TLIF procedure with local bone graft alone improved anterior vertebral translation, disc height, and lumbar lordosis. A proper surgical technique with adequate discectomy and facetectomy would contribute greatly to the improvement of the radiological parameters; however, this improvement was not maintained at the latest follow up.
\end{abstract}

Keywords: Vertebral translation, Radiological, Lumbar

\section{INTRODUCTION}

Spinal stability is the vertebral ability to maintain their relationship and limit their relative displacements during physiologic postures and loads. ${ }^{1}$ Instability develops when the spinal stabilizing system fails to maintain the physiological limit of spinal-neutral zonal, which may result in progressive deterioration of the structural components of the spine leading to incapacitating symptoms [e.g., low back pain (LBP) with or without sciatica, increasing disability and progressive deterioration of quality of life]. The concept of-lumbar segmental instability (LSI) is not new and degenerative and lytic spondylolisthesis comprises the principal etiology. The 
clinical symptoms and proposed clinical tests had limited diagnostic significance, hence the radiological criteria have been emphasized. ${ }^{2,3}$ Although the initial treatment is conservative (e.g., patient education, exercise, bracing, physical therapy), surgery is the last resort for symptomatic instability. ${ }^{4}$

Here we conducted a prospective comparative study to compare the functional and radiological results of local bone grafts with interbody fusion device (cage) to stand alone bone graft, in patients undergoing transforaminal lumbar interbody fusion (TLIF) surgery.

\section{METHODS}

\section{Study design and duration}

This hospital based prospective randomized comparative study design between 2 groups included patients of both sex attending S. M. S. hospital Jaipur, from April 2018 to June 2019 or till sample size was achieved, with due permission from the institutional ethical committee and review board and after taking written informed consent from the patients.

\section{Sample size calculation}

As per JOA sample size was calculated as 36 subjects for each of the 2 groups at alpha error 0.05 and power $80 \%$ assuming minimum difference of means to be detected in JOA scoring in autologous bone graft and interbody fusion cage in a modified transforaminal lumbar interbody fusion (TLIF) with standard deviation (as per seed article).

\section{Methodology}

This prospective study analyzed clinical data of 36 patients in each group with lumbar canal stenosis/degenerative lumbar instability who were operated from April 2018 to June 2019/till sample size achieved. This study was approved by the ethics committee of our institution. All patients were taken after signed informed consent. Follow ups seen at 6,12 week and 6,12 months after surgery.

\section{Inclusion criteria}

Inclusion criteria for the study included patients attending orthopedics OPD S. M. S. hospital Jaipur with lumbar canal stenosis/degenerative disc disease, patients/attendants giving written and informed consent for study, patients of both sex and age and patients who were fit for surgery.

\section{Exclusion criteria}

Exclusion criteria excluded the patients with other comorbid conditions affecting outcome variables, patients with immunocompromised state or taking long term steroid therapy and patients with pre-existing malignancy.

\section{Data analysis}

Data was recorded as per Performa. The data analysis was computer based; SPSS-22 was used for analysis. For categoric variables chi-square test was used. For continuous variables independent samples' t-test was used. $P$ value $<0.05$ was considered as significant.

\section{RESULTS}

Group A=bone graft and CAGE and, group B=stand-alone bone graft.

Table 1: Age wise comparison of the study groups.

\begin{tabular}{|llll|}
\hline Groups & Mean & SD & P value \\
\hline Group A & 48.41 & 2.56 & \multirow{2}{*}{0.56} \\
\hline Group B & 47.53 & 2.01 & \\
\hline
\end{tabular}

Group A showed mean age 48.41 years and group B showed 47.53 year. Comparison of mean score of age showed statistically non-significant results.

Table 2: Gender wise comparison of the study groups.

\begin{tabular}{|lll|}
\hline Gender & Group A $(\%)$ & Group B (\%) \\
\hline Male & $17(47.3)$ & $16(44.4)$ \\
\hline Female & $19(52.7)$ & $20(55.6)$ \\
\hline
\end{tabular}

$P$ value $=0.45$

Females were recorded higher as compared to male in both groups A and group B.

Table 3: Inter groups comparison of VAS score among group $A$ and $B$ at different time interval.

\begin{tabular}{|llllll|}
\hline \multirow{2}{*}{ Intervals } & \multicolumn{2}{l}{ Group A } & \multicolumn{2}{l}{ Group B } & P \\
& Mean & SD & Mean & SD & value \\
\hline Pre-op & 8.71 & 0.56 & 8.61 & 0.35 & 0.59 \\
\hline 6 weeks & 7.26 & 0.48 & 7.05 & 0.55 & 0.66 \\
\hline 12 weeks & 5.56 & 0.23 & 5.23 & 0.74 & 0.87 \\
\hline $\begin{array}{l}\text { 6 } \\
\text { months }\end{array}$ & 4.22 & 0.15 & 3.56 & 0.56 & 0.52 \\
\hline $\begin{array}{l}\text { 12 } \\
\text { months }\end{array}$ & 1.23 & 0.01 & 1.19 & 0.5 & 0.16 \\
\hline
\end{tabular}

Table 3 showed inter groups comparison of VAS score among group $\mathrm{A}$ and $\mathrm{B}$ at different time interval. By comparison of group A and B with unpaired t test, it showed statistically non-significant results.

Table 4 showed inter groups comparison of ODI score among group $\mathrm{A}$ and $\mathrm{B}$ at different time interval. By comparison of group $\mathrm{A}$ and $\mathrm{B}$ with unpaired $\mathrm{t}$ test, it showed statistically non-significant results.

Table 5 showed inter groups comparison of radiological fusion rate among group $\mathrm{A}$ and $\mathrm{B}$ at different time interval. By comparison of group A and B with unpaired $t$ test, it showed statistically non-significant results. 
Table 4: Inter groups comparison of ODI score among group $A$ and $B$ at different time interval.

\begin{tabular}{|c|c|c|c|c|c|}
\hline \multirow[t]{2}{*}{ Intervals } & \multicolumn{2}{|l|}{$\begin{array}{l}\text { Group } \\
\text { A }\end{array}$} & \multicolumn{2}{|l|}{$\begin{array}{l}\text { Group } \\
\text { B }\end{array}$} & \multirow{2}{*}{$\begin{array}{l}\mathbf{P} \\
\text { value }\end{array}$} \\
\hline & Mean & SD & Mean & SD & \\
\hline Pre-op & 75.47 & 2.77 & 75.31 & 2.7 & 0.54 \\
\hline 6 weeks & 53.2 & 1.92 & 51.6 & 2.41 & 0.52 \\
\hline 12 weeks & 41.12 & 1.56 & 40.98 & 1.23 & 0.23 \\
\hline $\begin{array}{l}6 \\
\text { months }\end{array}$ & 40.89 & 1.12 & 40.87 & 1.78 & 0.11 \\
\hline $\begin{array}{l}12 \\
\text { months }\end{array}$ & 35.89 & 1.11 & 34.12 & 1.09 & 0.3 \\
\hline
\end{tabular}

Table 5: Radiological fusion rate (grades) outcome in patients among groups.

\begin{tabular}{|l|lll|}
\hline $\begin{array}{l}\text { Fusion } \\
\text { rate }\end{array}$ & $\begin{array}{l}\text { Group A } \\
\text { Number of } \\
\text { patients }\end{array}$ & $\begin{array}{l}\text { Group B } \\
\text { Number of } \\
\text { patients }\end{array}$ & P value \\
\hline 12 weeks & 6 & 7 & 0.56 \\
\hline $\begin{array}{l}\text { 6 } \\
\text { months }\end{array}$ & 21 & 20 & 0.84 \\
\hline $\begin{array}{l}\text { 12 } \\
\text { months }\end{array}$ & 36 & 36 & 0.87 \\
\hline
\end{tabular}

\section{DISCUSSION}

Interbody fusion is one of the most common types of vertebral body fusions, and it is the soundest biomechanical technique. Inventions of many cages were prompted due to the popularity of interbody fusion. ${ }^{3,7}$ In posterolateral fusion (PLF), there is a risk of muscular fibrosis caused by the extensive release of muscles adjacent to the transverse process and increased blood loss and postoperative wound infection due to increased operative time. On the other hand, interbody fusion was advantageous for increasing the fusion rate with no need for extensive muscle release around the transverse process, graft was under compression force, and there was high rate of fusion. ${ }^{5} 360^{\circ}$ fusion has a lesser rate of pseudoarthrosis.

In TLIF, iliac crest is considered as an ideal source of graft. An iliac crest bone graft facilitates rapid bone union, but increases the risk of donor site pain, infection, excessive blood loss, pelvic fracture, an additional skin incision, and lengthy operative time. In contrast, a local bone graft consisting of the lamina as well as articular and spinous processes obtained from decompression can shorten the operative time and reduce blood loss. Various studies had reported that local bone chips obtained from decompression can be used as bone grafts which demonstrate comparable fusion rates with the iliac crest. ${ }^{6}$ Therefore, local bone has already become a frequently used bone graft substitute instead of iliac crest.

The graft expanders allograft has risk of disease transmission, while demineralized bone matrix, artificial bone, rh BMP has risk of heterotopic ossification and cancer. ${ }^{7}$ It is also expensive. ${ }^{8}$ The fusion obtained is dependent on the graft placed in the interbody region and failure to fuse will eventually led to implant failure. The fusion rate for local autogenous graft is $98.3 \%$ and iliac graft for $96.3 \% .^{1,7}$ The fusion rate with local graft was $72.4 \%$ after six months and $100 \%$ after 12 months. ${ }^{9}$ Hashimoto et al reported a fusion rate of $100 \%$ at two years after PLIF with local bone mixed with apatite and Wollastonite-Glass ceramic (AW-GC) grafted in a single intervertebral space. ${ }^{11}$ Nemoto observed $96 \%$ fusion rate in the titanium at 12 months. ${ }^{9}$

Autologous iliac bone graft has been considered the gold standard to achieve solid bone fusion, yet donor site complications are high including hematoma formation, infection, sensory deficit, reoperation, and chronic pain. ${ }^{10}$ Allograft and artificial bones have less ability for bone healing. and allograft may also have a risk for blood borne disease transmission. ${ }^{10}$ Many of these complications and disadvantages can be circumvented by the use of local bone chips obtained from the laminectomy. ${ }^{11}$

\section{Limitations}

Limitations of the study were-the time duration was limited and the sample size was less.

\section{CONCLUSION}

In the current series, the TLIF procedure with local bone graft alone improved anterior vertebral translation, disc height, and lumbar lordosis. A proper surgical technique with adequate discectomy and facetectomy would contribute greatly to the improvement of the radiological parameters; however, this improvement was not maintained at the latest follow up. This can be explained by the fact that cortico-cancellous bone chips do not provide immediate mechanical support; however, in the presence of pedicle screws, the fixation becomes a fairly rigid construct adequate for spinal fusion to occur. This fact is supported in our series, where we had neither definite pseudoarthrosis nor implant failures. Both clinical and radiologic outcomes are considered to be satisfactory with low complication rate. Given these considerations, it would seem that the use of TLIF with local bone graft alone is a good option for single level Instability; however, care should be taken in managing cases with high mechanical demands such as high grade listhesis, as these cases need efficient anterior column support (interbody cage) beside the biological properties of the local bone graft for fusion.

Funding: No funding sources

Conflict of interest: None declared

Ethical approval: The study was approved by the institutional ethics committee

\section{REFERENCES}

1. Guillot M, Fournier J, Scheye T, Escande G, Chazal $\mathrm{J}$, Tanguy A et al. Mechanics of the characteristic 
geometry of the human spine undergoing vertical pressure. Bull Assoc Anat (Nancy). 1990;74:78.

2. Alqarni AM, Schneiders AG, Hendrick PA. Clinical tests to diagnose lumbar segmental instability: A systematic review. J Orthop Sports Phys Ther. 2011;41:13040.

3. Posner I, White AA $3^{\text {rd }}$, Edwards WT, Hayes WC. A biomechanical analysis of the clinical stability of the lumbar and lumbosacral spine. Spine (Phila $\mathrm{Pa}$ 1976).1982;7:37489.

4. Fritz JM, Erhard RE, Hagen BF. Segmental instability of the lumbar spine. Phys Ther. 1998;78:88996.

5. Kim KT, Suk KS, Kim JM. Future development of interbody fusion cages. J Korean Soc Spine Surg. 2001;8:386491

6. Hitchon PW, Goel V, Rogge T, Dooris A, Drake J, Torner $\mathbf{J}$ et al. Spinal stability with anterior or posterior ray threaded fusion cages. J Neurosurg. 2000;93:1028.

7. Gologorsky Y, Skovrlj B, Steinberger J, Moore M, Arginteanu M, Moore F et al. Increased incidence of pseudarthrosis after unilateral instrumented transforaminal lumbar interbody fusion in patients with lumbar spondylosis: Clinical article. J Neurosurg Spine. 2014;21:6017.
8. Giannoudis PV, Dinopoulos H, Tsiridis E. Bone substitutes: an update. Injury. 2005; 36(3):S20-27.

9. Carragee EJ, Chu G, Rohatgi R, Hurwitz EL, Weiner BK, Yoon ST et al. Cancer risk after use of recombinant bone morphogenetic protein-2 for spinal arthrodesis. J Bone Joint Surg Am. 2013;95(17):153745.

10. Miura Y, Imagama S, Yoda M, Mitsuguchi H, Kachi $\mathrm{H}$. Is local bone viable as a source of bone graft in posterior lumbar interbody fusion? Spine (Phila $\mathrm{Pa}$ 1976). 2003;28:2386-9.

11. Hashimoto T, Shigenobu K, Kanayama M. Clinical results of single-level posterior lumbar interbody fusion using the Brantigan I/F carbon cage filled with a mixture of local morselized bone and bioactive ceramic granules. Spine (Phila $\mathrm{Pa}$ 1976). 2002;27:258-62.

Cite this article as: Gupta AK, Rathore JS, Bhati LS, Rathore DS, Meena RC. Functional and radiological comparison of transforaminal lumbar interbody fusion method with interbody fusion device versus stand-alone bone graft in lumbar canal stenosis or degenerative lumbar instability. Int J Res Orthop 2021;7:291-4. 